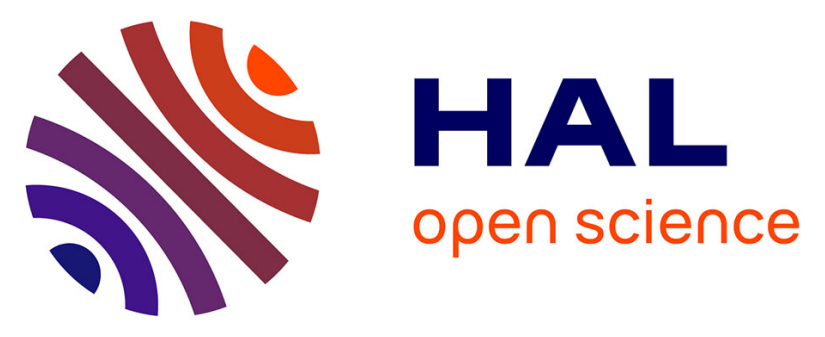

\title{
Early Identification of Patients at Risk for Difficult Intubation in the Intensive Care Unit. Development and Validation of the MACOCHA Score in a Multicenter Cohort Study AT A GLANCE COMMENTARY Scientific Knowledge on the Subject
}

Audrey de Jong, Nicolas Molinari, Nicolas Terzi, Nicolas Mongardon, Jean-Michel Arnal, Christophe Guitton, Bernard Allaouchiche, Catherine Paugam-Burtz, Jean-Michel Constantin, Jean-Yves Lefrant, et al.

\section{To cite this version:}

Audrey de Jong, Nicolas Molinari, Nicolas Terzi, Nicolas Mongardon, Jean-Michel Arnal, et al.. Early Identification of Patients at Risk for Difficult Intubation in the Intensive Care Unit. Development and Validation of the MACOCHA Score in a Multicenter Cohort Study AT A GLANCE COMMENTARY Scientific Knowledge on the Subject. American Journal of Respiratory and Critical Care Medicine, 2013, 187 (8), pp.832 - 839. 10.1164/rccm.201210-1851OC . hal-02549587

\section{HAL Id: hal-02549587 \\ https://hal.umontpellier.fr/hal-02549587}

Submitted on 21 Apr 2020

HAL is a multi-disciplinary open access archive for the deposit and dissemination of scientific research documents, whether they are published or not. The documents may come from teaching and research institutions in France or abroad, or from public or private research centers.
L'archive ouverte pluridisciplinaire HAL, est destinée au dépôt et à la diffusion de documents scientifiques de niveau recherche, publiés ou non, émanant des établissements d'enseignement et de recherche français ou étrangers, des laboratoires publics ou privés. 


\section{Early Identification of Patients at Risk for Difficult Intubation in the Intensive Care Unit Development and Validation of the MACOCHA Score in a
Multicenter Cohort Study}

Audrey De Jong ${ }^{1}$, Nicolas Molinari ${ }^{2}$, Nicolas Terzi ${ }^{3}$, Nicolas Mongardon ${ }^{4}$, Jean-Michel Arnal ${ }^{5}$, Christophe Guitton 6 , Bernard Allaouchiche7, Catherine Paugam-Burtz ${ }^{8,9}$, Jean-Michel Constantin ${ }^{10}$, Jean-Yves Lefrant ${ }^{11}$, Marc Leone ${ }^{12}$, Laurent Papazian'13, Karim Asehnoune ${ }^{14}$, Nicolas Maziers ${ }^{15}$, Elie Azoulay ${ }^{15}$, Gael Pradel ${ }^{16}$, Boris Jung 1,17, Samir Jaber1,17, and AzuRéa Network for the Frida-Réa Study Group*

${ }^{1}$ Intensive Care and Anesthesiology Department, University of Montpellier Saint Eloi Hospital, Montpellier, France; ${ }^{2}$ Department of Statistics, University of Montpellier Lapeyronie Hospital, UMR 729 MISTEA, Montpellier, France; ${ }^{3}$ INSERM, U1075, University of Caen, CHRU Caen, Service de Réanimation Médicale, Caen, France; ${ }^{4}$ Medical Intensive Care, Cochin Hospital, Assistance Publique des Hôpitaux de Paris Université Paris Descartes, Sorbonne Paris Cité, Paris, France; ${ }^{5}$ Intensive Care Department, Sainte Musse Hospital, Toulon, France; ${ }^{6}$ Medical Intensive Care Unit, Hôtel-Dieu Teaching Hospital, Nantes, France; ${ }^{7}$ Department of Anesthesiology and Critical Care Medicine, Edouard-Herriot Teaching Hospital, Hospices Civils de Lyon, Lyon, France; ${ }^{8}$ Intensive Care and Anesthesiology Department, University of Paris Diderot, Sorbonne Paris Cité, Paris, France; ${ }^{9} \mathrm{AP}-\mathrm{HP}$, Hôpital Beaujon, Paris, France; ${ }^{10}$ Intensive Care and Anesthesiology Department, Hotel-Dieu Hospital, University Hospital of Clermont Ferrand, Clermont-Ferrand, France; ${ }^{11}$ Intensive Care and Anesthesiology Department, University of Montpellier, Nimes Hospital, Nimes, France; ${ }^{12}$ Intensive Care and Anesthesiology Department and ${ }^{13}$ Medical Intensive Care Unit, University Hospital, Nord Hospital, Marseille, France; ${ }^{14}$ Intensive Care and Anesthesiology Department, University of Nantes, Hotel-Dieu Hospital, Nantes, France; ${ }^{15}$ Medical Intensive Care Unit, University of Paris-Diderot, Saint Louis Hospital, Paris, France; ${ }^{16}$ Intensive Care Department, Centre Hospitalier d'Avignon, Avignon, France; and ${ }^{17}$ Unité U1046 de I'Institut National de la Santé et de la Recherche Médicale (INSERM), University of Montpellier, Montpellier, France

Rationale: Difficult intubation in the intensive care unit (ICU) is a challenging issue.

Objectives: To develop and validate a simplified score for identifying patients with difficult intubation in the ICU and to report related complications.

Methods: Data collected in a prospective multicenter study from 1,000 consecutive intubations from 42 ICUs were used to develop a simplified score of difficult intubation, which was then validated externally in $\mathbf{4 0 0}$ consecutive intubation procedures from 18 other ICUs and internally by bootstrap on 1,000 iterations.

Measurements and Main Results: In multivariate analysis, the main predictors of difficult intubation (incidence $=11.3 \%$ ) were related to patient (Mallampati score III or IV, obstructive sleep apnea syndrome, reduced mobility of cervical spine, limited mouth opening); pathology (severe hypoxia, coma); and operator (nonanesthesiologist). From the $\beta$ parameter, a seven-item simplified score (MACOCHA score) was built, with an area under the curve (AUC) of 0.89 (95\% confidence interval [CI], 0.85-0.94). In the validation cohort (prevalence of difficult intubation $=8 \%)$, the AUC was $0.86(95 \% \mathrm{Cl}, 0.76-0.96)$, with a sensitivity of $73 \%$, a specificity of $89 \%$, a negative predictive value of $98 \%$, and

* A complete list of members may be found before the beginning of the REFERENCES. Supported by University Hospital of Montpellier.

Author Contributions: A.D.J., study concept and design, site training, data analysis and interpretation, manuscript preparation, and drafting. N. Molinari, study design, statistical methods, statistical data analysis, and manuscript review. N.T. N. Mongardon, J.-M.A., C.G., B.A., C.P.-B., J.-M.C., J.-Y.L., M.L., L.P., K.A., N. Maziers, E.A., and G.P., acquisition of the data and manuscript critique and review. B..., study concept and design, data analysis, and manuscript preparation. S.J., senior coordinator, study concept and design, site training and recruitment, data analysis, and manuscript preparation. All authors approved the manuscript submitted.

Correspondence and requests for reprints should be addressed to Samir Jaber M.D., Ph.D., Unité de Réanimation-Département d'Anesthésie-Réanimation B, University Hospital, $\mathrm{CHU}$ de Montpellier Hopital Saint Eloi, 80, Avenue Augustin Fliche, 34295 Montpellier Cedex 5, France. E-mail: s-jaber@chu-montpellier.fr

\section{AT A GLANCE COMMENTARY}

Scientific Knowledge on the Subject

Risk factors for difficult intubation are well described in anesthesiology. However, in the intensive care unit (ICU), they have yet to be identified in prospective multicenter studies and no prediction score has been validated. Additionally, association between difficult intubation and related complications has not been studied in prospective studies.

What This Study Adds to the Field

Seven clinical items available in the ICU were identified as independent risk factors for difficult intubation and constituted the MACOCHA score. This study develops and validates a prediction score for difficult intubation in the ICU. This score demonstrated good performance in the original cohort, after external validation in a validation cohort and internal validation with bootstrap. Moreover, difficult intubation was strongly associated with moderate and severe life-threatening complications related to intubation.

a positive predictive value of $36 \%$. After internal validation by bootstrap, the AUC was $0.89(95 \% \mathrm{Cl}, 0.86-0.93)$. Severe life-threatening events (severe hypoxia, collapse, cardiac arrest, or death) occurred in $38 \%$ of the 1,000 cases. Patients with difficult intubation $(n=113)$ had significantly higher severe life-threatening complications than those who had a nondifficult intubation ( $51 \%$ vs. $36 \% ; P<0.0001)$.

Conclusions: Difficult intubation in the ICU is strongly associated with severe life-threatening complications. A simple score including seven clinical items discriminates difficult and nondifficult intubation in the ICU.

Clinical trial registered with www.clinicaltrials.gov (NCT 01532063).

Keywords: difficult intubation; score; critical care; complications; mortality 
In the intensive care unit (ICU), intubation is a challenging issue (1-3) because it may be associated with life-threatening complications in up to one-third of cases $(1,2)$. Difficult intubation is known to be associated with life-threatening complications in the operating room (4) and in emergent conditions (5-7). Although several predictive risk factors and scores for difficult intubation were identified in anesthesia practice, to our knowledge none have been identified for ICU patients. Such patients differ from those undergoing elective surgery, with a high rate of acute respiratory or hemodynamic failure and with worse intubation conditions than in the operative room. Early identification of risk factors for difficult intubation could allow for anticipation and preparation of adequate material, use of an alternative intubation strategy, and call on additional assistance before intubation and thus reduce morbidity $(5,8)$.

Only retrospective studies $(9,10)$ have assessed the relationship between complications and difficult intubation. A study performed outside the operative room (9) reported that hypoxemia was sevenfold higher in case of difficult intubation in comparison with nondifficult intubation. Another study (10) in the emergency area showed that difficult intubation was associated with airway complication. Furthermore, the incidence of difficult intubation the ICU is highly variable across studies, ranging from 1 to $23 \%$, depending on the center and the definition of difficult intubation (10-13).

The main objective of this study was to identify specific risk factors for difficult ICU intubation so as to develop and validate a simplified score predicting difficult intubation. This score was intended to include items that are clinically easily identifiable, applicable at bedside, and simple and clear to use. The secondary objectives were to assess the relationship between difficult intubation and complications and to establish the incidence of difficult intubation in a representative sample of ICU patients.

\section{METHODS}

\section{Study Design and Population}

A prospective, observational, multicenter study was conducted in 42 ICUs to develop a predictive model for difficult intubation (original cohort), and in 18 ICUs to validate the model (validation cohort). All adult patients consecutively intubated in the ICU were included. Exclusion criteria were pregnancy, refusal to participate after information was provided, or age younger than 18 years. See the online supplement for more information.

\section{Ethics and Consent}

Because of the observational, noninvasive design of this study, the need for written consent was waived. The local ethics committee, Comité de Protection des Personnes Sud-Mediterranée III, approved the study design (code UF:8819, register:2011-A001122-39). See the online supplement for more information.

\section{Data Collection}

Clinical parameters were prospectively assessed before, during, and after intubation procedures (see the online supplement and tables)

\section{Definition of Difficult Intubation and Complications}

Difficult intubation was defined as three or more laryngoscopic attempts to place the endotracheal tube into the trachea or as lasting more than 10 minutes using conventional laryngoscopy (14). Severe life-threatening complications $(1,2)$ were defined as death; cardiac arrest; severe cardiovascular collapse, defined as systolic blood pressure less than $65 \mathrm{~mm} \mathrm{Hg}$ recorded at least one time or less than $90 \mathrm{~mm} \mathrm{Hg}$ that lasted 30 minutes despite $500-1,000 \mathrm{ml}$ of fluid loading (crystalloids or colloids solutions) or requiring introduction of vasoactive support; or severe hypoxemia (decrease in oxygen saturation as measured by pulse oximetry $<80 \%$ during attempts).

Mild to moderate complications $(1,2)$ were defined as esophageal intubation; aspiration of gastric contents (migration of stomach contents into the lung); supraventricular or ventricular arrhythmia (without pulseless rhythm) that required therapy; dangerous agitation (Richmond Agitation-Sedation Scale score $>3$ ); or dental injury.

\section{Statistical Analysis}

See the online supplement for more information. The number of subjects needed was calculated to obtain composite criteria of difficult intubation with a sensitivity of $80 \pm 10 \%$ based on a $9 \%$ incidence of difficult intubation, resulting in an estimated 700 intubation procedures. We decided to include 1,000 intubation procedures to develop the model in the original cohort, taking into account missing data, and 400 intubation procedures to externally validate the model in the validation cohort.

A logistic regression was used to identify risk factors for difficult intubation in the original cohort. A multivariate model was established to predict difficult intubation. Variables were selected if $P$ value was less than 0.20 in the univariate analysis and a stepwise procedure was used to select the final model. To establish a simplified score, we gave a score to each of the variables included in the final prediction model in relation to each one's $\beta$ parameter (regression coefficient) in that model (15). The discriminative ability of the score (sensitivity, specificity, positive predictive value, negative predictive value, positive and negative likelihood ratio) was estimated in both cohorts to externally validate the simplified score $(15,16)$, and receiver operating characteristic (ROC) curve was established to estimate the area under the curve (AUC) of the simplified score. We used the bootstrap to internally validate the simplified score by sampling with replacement for 1,000 iterations (17). A $P$ value of less than or equal to 0.05 was considered statistically significant.

\section{RESULTS}

See the online supplement for more information. During the study period, 1,400 intubation procedures were studied in 1,360 patients. From September 1, 2011 to January 31, 2012, 1,000 intubation procedures performed in 972 patients from 42 centers were included in the original cohort. All the intubation procedures were included. Twenty-eight patients $(0.28 \%)$ were intubated twice. The median (interquartile range) number of intubation procedures included by center was 15 (10-20). Then, from February 1, 2012 to April 1, 2012, 400 intubation procedures performed in 388 patients from 18 other centers were included in the validation cohort. Twelve patients were intubated twice. The median (interquartile range) number of intubation procedures included by center was $15(11-28)$. The flow chart of the study is shown in Figure 1.

Incidence of difficult intubation was $11.3 \%$ (113 of 1,000 intubation procedures) in the original cohort and $8 \%$ (32 of 400 intubation procedures) in the validation cohort $(P=0.07)$.

Tables 1 and E1 show the characteristics of patients in original and validation cohorts according to the difficulty of intubation. In both cohorts, there were significantly more patients with body mass index (BMI) greater than or equal to $30 \mathrm{~kg} / \mathrm{m}^{2}$ in difficult intubation groups. In the original cohort, increased Simplified Acute Physiology Score II score and coma as a reason for intubation was significantly associated with difficult intubation.

The operator status and main variables obtained before intubation are reported in Tables 2 and E2 (see Table E2 in the online supplement). In the original cohort, preintubation saturation less than $80 \%$ was significantly associated with difficult intubation, whereas noninvasive ventilation (NIV) was associated with the absence of difficult intubation. The drugs used for intubation, in particular neuromuscular blockers, did not differ between groups (see Table E3). However, midazolam use was more frequent in case of difficult intubation. The main parameters observed before 


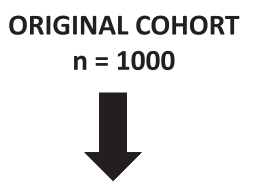

Admissions to ICU

(42 centers, 402 beds) $n=7820$<smiles>CCOC</smiles>

Enrolled :

adult consecutive

intubation procedures in ICU $\mathrm{n}=1000(13 \%)$

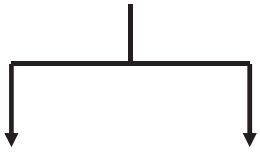

Difficult

intubation

$n=113(11 \%)$

No difficult

intubation

$n=887(89 \%)$
VALIDATION COHORT

$n=400$

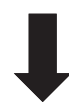

Admissions to ICU

(18 centers, 178 beds) $\mathrm{n}=3330$

Enrolled:

adult consecutive

intubation procedures in ICU $n=400(12 \%)$

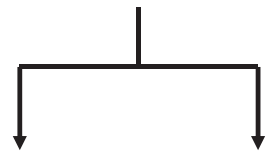

Difficult intubation $n=32(8 \%)$
No difficult intubation $n=368(92 \%)$

Figure 1. Patient flow diagram. ICU = intensive care unit.

the intubation procedure are shown in Tables 3 and E4. In the original cohort, Guedel use, difficult mask ventilation, plastic laryngoscope blade, Mallampati score, previous documented difficult intubation, limited mouth opening, elevated neck circumference, reduced mobility of cervical spine, obstructive sleep apnea syndrome (OSAS), head and neck pathology, presence of teeth, snoring, and need to release the Sellick maneuver

for intubation were significantly associated with difficult intubation. The nonanesthesiologist status of the operator was also associated with difficult intubation, whether an expert operator or not. No statistical interaction was found between nonanesthesiologist status and operator expertise $(P=0.84)$. Moreover, we performed a logistic regression to assess the risk factors of nonassessment of the Mallampati score in the original cohort $(\mathrm{n}=234 ; 23 \%)$. The risk factors in the final multivariate model (see Table E5) were head and neck disease, limited mouth opening, the need to replace the endotracheal tube, and coma. Center effect was not significant in the final model. The main evaluated parameters and physiologic variables during the intubation procedure are presented in Table E6. In both cohorts, heart rate and oxygen saturation as measured by pulse oximetry during intubation were significantly decreased in difficult intubation groups. Components of the Intubation Difficulty Scale (IDS) score were also associated with difficult intubation.

In the final multivariate model constructed with the 694 intubation procedures and all available data, adjusted for age, the main predictors of difficult intubation were related to the patient (Mallampati score III or IV, OSAS, reduced mobility of cervical spine, limited mouth opening), the pathology (coma, severe hypoxia), and the operator (nonanesthesiologist) (Table 4). Center effect was assessed both as fixed and random effect, but was not significant in the final model. The goodness of fit, assessed by the Hosmer and Lemeshow test, was of 0.94. The AUC was at 0.90 (95\% confidence interval [CI], 0.86-0.93).

The simplified score (MACOCHA score) built from the final model is described in Table 5, ranging from 0 to 12 . The goodness of fit, assessed by the Hosmer and Lemeshow test, demonstrated no statistical evidence of lack of fit $(P=0.20)$ and the AUC was at 0.89 (95\% CI, 0.85-0.94). When the score was applied to the validation cohort, the goodness of fit assessed

TABLE 1. PATIENT CHARACTERISTICS AND REASONS FOR ICU ADMISSION AND INTUBATION IN ORIGINAL AND VALIDATION COHORTS ACCORDING TO DIFFICULT INTUBATION

\begin{tabular}{|c|c|c|c|c|c|c|c|c|}
\hline & \multicolumn{4}{|c|}{ Original Cohort } & \multicolumn{4}{|c|}{ Validation Cohort } \\
\hline & $\begin{array}{c}\text { Total } \\
(n=1,000)\end{array}$ & $\begin{array}{l}\text { Difficult Intubation } \\
\quad(n=113)\end{array}$ & $\begin{array}{l}\text { No Difficult Intubation } \\
\quad(n=887)\end{array}$ & $\begin{array}{c}P \\
\text { Value }\end{array}$ & $\begin{array}{c}\text { Total } \\
(n=400)\end{array}$ & $\begin{array}{l}\text { Difficult Intubation } \\
\qquad(n=32)\end{array}$ & $\begin{array}{l}\text { No Difficult Intubation } \\
(n=368)\end{array}$ & $\begin{array}{c}P \\
\text { Value }\end{array}$ \\
\hline Age, yr & $62(51-73)$ & $61(51-68)$ & $62(51-73)$ & 0.09 & $63(48-74)$ & $58(45-69)$ & $64(49-74)$ & 0.13 \\
\hline Sex, male & $624 / 979(64)$ & $68 / 111(61)$ & $556 / 868(64)$ & 0.56 & $262 / 397(66)$ & $20 / 32(63)$ & $242 / 365(66)$ & 0.66 \\
\hline SAPS2 & $48(36-62)$ & $53(38-66)$ & $47(36-61)$ & 0.05 & $48(36-61)$ & $41(31-56)$ & $49(36-62)$ & 0.09 \\
\hline SOFA & $6(4-8)$ & $6(3-8)$ & $6(4-8)$ & 0.77 & $5(3-8)$ & $5(3-7)$ & $5(3-8)$ & 0.58 \\
\hline Weight, kg & $71(60-85)$ & $76(63-90)$ & $70(60-85)$ & 0.03 & $70(60-80)$ & $70(64-83)$ & $70(60-80)$ & 0.41 \\
\hline Height, $\mathrm{cm}$ & $169(160-175)$ & $170(160-175)$ & $169(160-175)$ & 0.97 & $170(163-175)$ & $170(160-175)$ & $170(163-175)$ & 0.52 \\
\hline $\begin{array}{l}\text { Body mass index, } \\
\geqslant 30 \mathrm{~kg} / \mathrm{m}^{2}\end{array}$ & $219 / 933(23)$ & $37 / 110(34)$ & $182 / 823(22)$ & 0.007 & $63 / 378(17)$ & $9 / 29(31)$ & $54 / 349(15)$ & 0.03 \\
\hline Medical type of admission & $734(73)$ & $86(76)$ & $650(73)$ & 0.52 & $267(67)$ & $21(66)$ & $246(67)$ & 0.88 \\
\hline \multicolumn{9}{|l|}{ Reason for ICU admission } \\
\hline Acute respiratory failure & $455(46)$ & $45(40)$ & $410(46)$ & 0.20 & $209(52)$ & $18(56)$ & $191(52)$ & 0.64 \\
\hline Trauma & $42(4)$ & $6(5)$ & $36(41)$ & 0.53 & $33(8)$ & $0(0)$ & $33(9)$ & 0.08 \\
\hline Postoperative & $95(10)$ & $6(5)$ & $89(10)$ & 0.11 & $58(15)$ & $4(13)$ & $54(15)$ & 0.10 \\
\hline Cardiac arrest & $24(2)$ & $2(2)$ & $22(3)$ & 1.00 & $10(3)$ & $2(6)$ & $8(2)$ & 0.18 \\
\hline Neurologic & $250(25)$ & $37(33)$ & $213(24)$ & 0.04 & $68(17)$ & $4(13)$ & $54(15)$ & 0.48 \\
\hline Shock & $264(26)$ & $33(29)$ & $231(26)$ & 0.47 & $105(26)$ & $11(34)$ & $94(26)$ & 0.28 \\
\hline Ascitic decompensation & $29(3)$ & $3(2)$ & $26(3)$ & 1.00 & $2(1)$ & $0(0)$ & $2(1)$ & 1.00 \\
\hline Acute renal failure & $95(10)$ & $9(8)$ & $86(10)$ & 0.55 & $29(7)$ & $4(13)$ & $25(7)$ & 0.27 \\
\hline Others & $82(8)$ & $10(9)$ & $72(8)$ & 0.79 & $25(6)$ & $2(6)$ & $23(6)$ & 1.00 \\
\hline \multicolumn{9}{|l|}{ Reason for intubation } \\
\hline Acute respiratory failure & $632(63)$ & $63(56)$ & $569(64)$ & 0.08 & $253(63)$ & $20(63)$ & $233(63)$ & 0.93 \\
\hline Shock & $138(14)$ & $13(12)$ & $125(14)$ & 0.45 & $74(19)$ & $9(28)$ & $65(18)$ & 0.16 \\
\hline Coma & $252(25)$ & $39(35)$ & $213(24)$ & 0.02 & $73(18)$ & $9(28)$ & $66(18)$ & 0.16 \\
\hline Cardiac arrest & $30(3)$ & $4(4)$ & $26(3)$ & 0.77 & $11(3)$ & $1(3)$ & $10(3)$ & 0.61 \\
\hline $\begin{array}{l}\text { Replace the endotracheal } \\
\text { tube }\end{array}$ & $128(13)$ & $14(12)$ & $114(13)$ & 0.89 & $66(17)$ & $8(25)$ & $58(16)$ & 0.18 \\
\hline Others & $72(7)$ & $8(7)$ & $64(7)$ & 0.96 & $38(10)$ & $2(6)$ & $36(10)$ & 0.75 \\
\hline
\end{tabular}

Definition of abbreviations: ICU = intensive care unit; SAPS2 = Simplified Acute Physiologic Score; SOFA = Sequential Organ Failure Assessment.

Data are summarized as number (\%) or median (interquartile range). One patient can have more than one reason for ICU admission or for intubation. 
TABLE 2. OPERATOR STATUS AND MAIN VARIABLES OBTAINED BEFORE INTUBATION IN ORIGINAL AND VALIDATION COHORTS ACCORDING TO DIFFICULT INTUBATION

\begin{tabular}{|c|c|c|c|c|c|c|c|c|}
\hline & \multicolumn{4}{|c|}{ Original Cohort } & \multicolumn{4}{|c|}{ Validation Cohort } \\
\hline & $\begin{array}{c}\text { Total } \\
(n=1,000)\end{array}$ & $\begin{array}{l}\text { Difficult Intubation } \\
\qquad(n=113)\end{array}$ & $\begin{array}{l}\text { No Difficult Intubation } \\
\quad(n=887)\end{array}$ & $\begin{array}{c}P \\
\text { Value }\end{array}$ & $\begin{array}{c}\text { Total } \\
(n=400)\end{array}$ & $\begin{array}{l}\text { Difficult Intubation } \\
\qquad(n=32)\end{array}$ & $\begin{array}{l}\text { No Difficult Intubation } \\
\quad(n=368)\end{array}$ & $\begin{array}{c}P \\
\text { Value }\end{array}$ \\
\hline Daytime intubation & $380 / 965$ (39) & $36(33)$ & $344(40)$ & 0.13 & $129(34)$ & $13(43)$ & $116(33)$ & 0.24 \\
\hline First intubation & $643(64)$ & $67(59)$ & $576(65)$ & 0.24 & $250(63)$ & $15(47)$ & $235(64)$ & 0.06 \\
\hline Expert operator & $370(37)$ & $45(40)$ & $325(37)$ & 0.57 & $178(45)$ & $10(31)$ & $162(44)$ & 0.11 \\
\hline Anesthesiologist & $683(68)$ & $68(60)$ & $615(69)$ & 0.04 & $249(62)$ & $18(56)$ & $231(63)$ & 0.47 \\
\hline Number of operators & & & & 0.007 & & & & 0.40 \\
\hline 1 & 247/991 (25) & 18/109 (17) & $229 / 882(26)$ & & $129 / 396(33)$ & $8 / 31(26)$ & $121 / 365(33)$ & \\
\hline 2 & $630 / 991(64)$ & $70 / 109(64)$ & $560 / 882(63)$ & & $226 / 396(57)$ & $18 / 31(58)$ & $208 / 365(57)$ & \\
\hline 3 & $114 / 991(12)$ & $21 / 109$ (19) & $93 / 882(11)$ & & $41 / 396(10)$ & $5 / 31(16)$ & $36 / 365(10)$ & \\
\hline Informed patient & $619(62)$ & $61(54)$ & $558(63)$ & 0.07 & $276(69)$ & $23(72)$ & $253(69)$ & 0.71 \\
\hline Fluid loading before intubation & & & & 0.80 & & & & 0.99 \\
\hline 0 & $545(55)$ & $65(58)$ & $480(54)$ & & $208(52)$ & $18(56)$ & $190(52)$ & \\
\hline$<500 \mathrm{ml}$ & $165(16)$ & $15(13)$ & $150(17)$ & & $35(9)$ & $2(6)$ & $33(9)$ & \\
\hline $500-1000 \mathrm{ml}$ & $203(20)$ & $23(20)$ & $180(20)$ & & $91(23)$ & $7(22)$ & $84(23)$ & \\
\hline$>1,000 \mathrm{ml}$ & $87(8)$ & $10(9)$ & $77(9)$ & & $66(17)$ & $5(16)$ & $61(17)$ & \\
\hline Nonperceived blood pressure & $33(3)$ & $5(4)$ & $28(3)$ & 0.41 & $11(3)$ & $0(0)$ & $11(3)$ & 0.32 \\
\hline $\begin{array}{l}\text { Emergency characteristic of } \\
\text { intubation }\end{array}$ & & & & 0.26 & & & & 0.86 \\
\hline Real emergency & $445(46)$ & $47(42)$ & $398(45)$ & & $142(36)$ & $11(34)$ & $131(36)$ & \\
\hline Relative emergency & $464(46)$ & $51(45)$ & $413(47)$ & & $218(54)$ & $19(59)$ & $199(54)$ & \\
\hline Deferred emergency & $91(9)$ & $37(27)$ & $195(17)$ & & $40(10)$ & $2(6)$ & $33(9)$ & \\
\hline Vasopressors use & $210(21)$ & $22(19)$ & $188(21)$ & 0.67 & $78(20)$ & $4(13)$ & $74(20)$ & 0.30 \\
\hline $\mathrm{SBP}<90 \mathrm{~mm} \mathrm{Hg}$ & $239 / 908(26)$ & $27 / 103(26)$ & $212 / 805(26)$ & 0.98 & $113 / 372(30)$ & $11 / 31(36)$ & $102 / 341(30)$ & 0.52 \\
\hline $\mathrm{Sp}_{\mathrm{O}_{2}}<80 \%$ & $191 / 965(20)$ & $32 / 110(29)$ & $159 / 855(19)$ & 0.009 & $78 / 377(21)$ & $7 / 30(23)$ & $71 / 347(20)$ & 0.71 \\
\hline NIV & $361(36)$ & $28(25)$ & $333(38)$ & 0.008 & $148(37)$ & $13(41)$ & $135(37)$ & 0.66 \\
\hline Full stomach & $740(74)$ & $82(73)$ & $658(74)$ & 0.71 & $232(58)$ & $20(63)$ & $212(58)$ & 0.59 \\
\hline
\end{tabular}

Definition of abbreviations: NIV = noninvasive ventilation; $\mathrm{SBP}=$ systolic blood pressure; $\mathrm{Sp}_{\mathrm{O}_{2}}=$ oxygen saturation as measured by pulse oximetry

Data are summarized as number (\%) or median (interquartile range).

The emergency characteristic of intubation was categorized as follows: real emergency, intubation required without any delay; relative emergency, intubation required within 1 hour; deferred emergency, intubation required in more than 1 hour.

by Hosmer and Lemeshow test demonstrated no statistical evidence of lack of fit $(P=0.28)$ and the AUC was at $0.86(95 \%$ CI, 0.76-0.96). ROC curves associated with the simplified score in the original and validation cohorts are respectively presented in Figures E1A and E1B, and the frequency of difficult intubation across the range of the score is presented in Figures $2 \mathrm{~A}$ and 2B. In original and validation cohorts, using a cutoff of 3 or greater seems optimal in allowing a balance between excellent negative predictive value and good positive predictive value (see Tables E7A and E7B). In validation cohort, at the cutoff point of three determined by ROC analysis, positive and negative predictive values $(95 \% \mathrm{CI})$ for difficult intubation were $36 \%$ and $98 \%$, respectively, with a sensitivity of $73 \%$ and a specificity of $89 \%$. After internal validation by bootstrap, the AUC of the simplified score was at 0.89 (95\% CI, 0.86-0.93).

When considering Mallampati score alone, the AUC was at 0.80 (95\% CI, 0.74-0.86), significantly lower than the AUC of the MACOCHA score $(0.89 ; 95 \%$ CI, 0.85-0.94; $P<0.0001$ ) (see Figure E2). Furthermore, the Hosmer and Lemeshow test demonstrated statistical evidence of lack of fit with data when using Mallampati score alone $(P=0.001)$. Therefore, using MACOCHA score permitted detection of 11 additional difficult intubations that would not have been detected by Mallampati score alone. The relative sensitivity of Mallampati score to MACOCHA score was $82 \%$ (51 of 62 ). Indeed, with the Mallampati score alone, 51 of 82 difficult intubation procedures were predicted at a cutoff point of three (sensitivity of $62 \%$ ), versus 62 of 82 at a cutoff point of three for the MACOCHA score (sensitivity of $76 \%)(P=0.002)$. In the development cohort, overall complications occurred in 437 of 1,000 intubation procedures $(43.7 \%)$, with 381 (38.1\%) severe complications (26 cardiac arrests, $2.6 \%$; five deaths, $0.5 \% ; 274$ severe collapses, $27.4 \%$; 155 severe hypoxemia, $15.5 \%)$ and $112(11.2 \%)$ moderate complications (15 agitations, 1.5\%; 32 cardiac arrhythmias, 3.2\%; 23 aspirations, $2.3 \%$; 48 esophageal intubations, $4.8 \%$; six dental injuries, $0.6 \%$ ). Figures $3 \mathrm{~A}$ and $3 \mathrm{~B}$ show the detailed percentage of complications according to the difficulty of intubation. Patients with difficult intubation in both (original and validation) cohorts (Figures $3 \mathrm{~A}$ and $3 \mathrm{~B}$ ) had significantly higher severe life-threatening complications than those who had nondifficult intubation.

Mortality was 299 (30\%) of 982 in the original cohort and was $35(32 \%)$ of 109 in the difficult intubation groups and $264(30 \%)$ of 873 in the nondifficult intubation groups $(P=0.69)$.

\section{DISCUSSION}

This is the first study to identify risk factors of difficult intubation in a large multicenter cohort of ICU patients. We developed and validated internally and externally a score for difficult intubation in the ICU (MACOCHA score). This study shows that a simple model easily applicable in clinical practice predicts absence of difficult intubation in the ICU. This study also reveals a high rate of severe morbidity related to difficult intubation in the ICU.

Anticipating difficult intubation is a challenging issue: in the present study, the complications of intubation were higher when intubation was difficult ( $65 \%$ vs. $41 \%$ overall, $51 \%$ vs. $36 \%$ considering severe life-threatening complications). As underlined by a recent report, $25 \%$ of major airway events in Great Britain occur in the ICU, revealing a poor identification of patients at risk (5). Rates of complications in the present study were in the range of previous studies, with the incidence of severe complications varying with the definitions used, but generally ranging between $20 \%$ (9) and 50\% (13). Additionally, airway complications in the report by Martin and coworkers (10) are comparable 


\begin{tabular}{|c|c|c|c|c|c|c|c|c|}
\hline & \multicolumn{4}{|c|}{ Original Cohort } & \multicolumn{4}{|c|}{ Validation Cohort } \\
\hline & $\begin{array}{c}\text { Total } \\
(n=1,000)\end{array}$ & $\begin{array}{l}\text { Difficult } \\
\text { Intubation } \\
(n=113)\end{array}$ & $\begin{array}{l}\text { No Difficult } \\
\text { Intubation } \\
(n=887)\end{array}$ & $\begin{array}{c}P \\
\text { Value }\end{array}$ & $\begin{array}{c}\text { Total } \\
(n=400)\end{array}$ & $\begin{array}{c}\text { Difficult } \\
\text { Intubation } \\
(n=32)\end{array}$ & $\begin{array}{l}\text { No Difficult } \\
\text { Intubation } \\
(n=368)\end{array}$ & $\begin{array}{c}P \\
\text { Value }\end{array}$ \\
\hline Preoxygenation & $946(95)$ & $106(94)$ & $840(95)$ & 0.69 & $374(94)$ & $31(97)$ & $343(97)$ & 0.71 \\
\hline Preoxygenation by NIV & $407(40)$ & $37(33)$ & $370(42)$ & 0.07 & $158(40)$ & $14(44)$ & $144(39)$ & 0.61 \\
\hline Guedel use & $94(9)$ & $17(15)$ & $77(9)$ & 0.03 & $35(9)$ & $6(19)$ & $29(8)$ & 0.05 \\
\hline Difficult mask ventilation & $73 / 392(19)$ & $20 / 64(31)$ & $53 / 328(16)$ & 0.005 & $22 / 184(12)$ & $4 / 26(15)$ & $18 / 158(11)$ & 0.52 \\
\hline Laryngoscope blade & & & & 0.006 & & & & 0.27 \\
\hline Plastic single-use & $70 / 965(7)$ & $14 / 107(13)$ & $56 / 858(7)$ & & $121 / 384(31)$ & 6/32 (19) & $115 / 352(33)$ & \\
\hline Metal single-use & $525 / 965(54)$ & $99 / 107(88)$ & $831 / 858(94)$ & & $192 / 384(50)$ & $19 / 32(59)$ & $173 / 352(49)$ & \\
\hline Metal reusable & $370 / 965(38)$ & $48 / 107(45)$ & $322 / 858(38)$ & & $71 / 384(19)$ & $7 / 32(22)$ & $64 / 352(18)$ & \\
\hline Mallampati score & & & & $<0.000001$ & & & & $<0.000001$ \\
\hline 1 & $493 / 766(64)$ & $20 / 84(24)$ & $473 / 682(69)$ & & $192 / 309(62)$ & $4 / 25(16)$ & $188 / 284(66)$ & \\
\hline ॥ & $180 / 766(24)$ & $11 / 84(13)$ & $169 / 682(25)$ & & $77 / 309(25)$ & $3 / 25(12)$ & $74 / 284(26)$ & \\
\hline III & $65 / 766(8)$ & $29 / 84(35)$ & $36 / 682(5)$ & & $29 / 309(9)$ & $10 / 25(40)$ & $19 / 284(7)$ & \\
\hline IV & $28 / 766(4)$ & $24 / 84(29)$ & $4 / 682(1)$ & & $11 / 309(4)$ & $8 / 25(32)$ & $3 / 284(1)$ & \\
\hline Previous documented difficult intubation & $23(2)$ & $9(8)$ & $14(2)$ & 0.0005 & $14(4)$ & $5(16)$ & $9(3)$ & 0.003 \\
\hline Limited mouth opening & $120(9)$ & $25(22)$ & $67(8)$ & $<0.000001$ & $28(7)$ & $6(19)$ & $22(6)$ & 0.02 \\
\hline Low thyromental distance & $107(11)$ & $15(13)$ & $92(10)$ & 0.35 & $44(11)$ & $4(13)$ & $40(11)$ & 0.77 \\
\hline Elevated neck circumference & $141(14)$ & $33(29)$ & $108(12)$ & $<0.000001$ & $37(9)$ & $6(19)$ & $31(8)$ & 0.10 \\
\hline Reduced mobility of cervical spine & $83(8)$ & $23(20)$ & $60(7)$ & $<0.000001$ & $31(8)$ & $5(16)$ & $26(7)$ & 0.09 \\
\hline Obstructive apnea syndrome & $78(8)$ & $33(29)$ & $45(5)$ & $<0.000001$ & $20(5)$ & $8(25)$ & $12(3)$ & 0.00004 \\
\hline Head and neck disease & $53(5)$ & $18(16)$ & $35(4)$ & $<0.000001$ & $18(5)$ & $3(9)$ & $15(4)$ & 0.17 \\
\hline Beard & $78(8)$ & $12(11)$ & $66(7)$ & 0.24 & $17(4)$ & $2(6)$ & $15(4)$ & 0.64 \\
\hline Toothless & $283(28)$ & $21(19)$ & $262(30)$ & 0.01 & $87(22)$ & $9(28)$ & $78(21)$ & 0.36 \\
\hline Snoring & $116(12)$ & $25(22)$ & $91(10)$ & 0.0002 & $28(7)$ & $5(16)$ & $23(6)$ & 0.06 \\
\hline Diabetes & $177(18)$ & $21(19)$ & $156(18)$ & 0.79 & $48(12)$ & $6(19)$ & $42(11)$ & 0.25 \\
\hline Sellick maneuver & $448(45)$ & $58(51)$ & $390(44)$ & 0.14 & $128(32)$ & $10(31)$ & $118(32)$ & 0.92 \\
\hline Need to release Sellick maneuver for intubation & $105 / 448(23)$ & $29 / 58(50)$ & $76 / 390(19)$ & $<0.000001$ & $18 / 128(14)$ & $4 / 10(40)$ & $14 / 118(12)$ & $<0.000001$ \\
\hline
\end{tabular}

Definition of abbreviation: NIV = noninvasive ventilation.

Data are summarized as number (\%) or median (interquartile range).

with our study $(\sim 4 \%)$. Likewise, rates of difficult ICU intubation ranged from $1 \%(13)$ to $23 \%$ (11) according to the definition used, around $10 \%$ on average $(13,18)$, which is consistent with our results. This large range of difficult ICU intubation rates may also be explained by the operator skill, which is not accounted for in the different definitions used (19).

In this study, we attempted to create a pragmatic, predictive difficult-intubation score. To our knowledge, it is the first time that such a predictive score (MACOCHA score) has been developed and validated in the ICU. The final model of the logistic regression in the original cohort is robust and presents very good characteristics, with very high AUC and excellent goodness of fit with data (20). The simplified score still presents very high AUC and matches well the observed data. By optimizing the discrimination threshold, the discriminative ability of the score is high. To reject difficult intubation with certainty, a cutoff of three or greater seems appropriate, allowing optimal negative predictive value $(97 \%$ and $98 \%$ in the original and validation cohorts, respectively) and sensitivity (76\% and $73 \%$ in the original and validation cohorts, respectively). However, the specificity $(90 \%$ and $89 \%$ ) and positive predictive values (48\% and $36 \%$ ) are lower, although improve with a threshold of four or greater (specificity of $93 \%$ and $92 \%$, positive predictive value of $53 \%$ and $42 \%$ ), whereas the negative predictive value remains very good $(96 \%$ and $97 \%)$. At positivity thresholds of five or higher, sensitivity losses are pronounced whereas further specificity advances are marginal.

Because of the low prevalence of difficult intubation on average ( $8 \%$ in the validation cohort), positive predictive value is low despite a good specificity (20). Nevertheless, to reject difficult intubation with certainty, the main value of the score resides in the negative predictive value of the parameter. It is prudent to be prepared for a difficult intubation, even if the intubation is finally not difficult. We performed an external validation to show the generalizability of the model. External validation is necessary before implementing prediction models in clinical practice (21). Results are concordant between the original and validation cohorts, with very close discriminatory values. The internal validation by bootstrap confirmed those results.

The MACOCHA score has the advantage of being constituted with easily identifiable and clinically pertinent variables. Furthermore, the items used in the MACOCHA score are close to those identified in the operating room and include risk factors strongly associated with difficult intubation in multiple studies performed in anesthesiology $(18,22-25)$. Additionally, Hiremath and coworkers (26) showed that patients known to be difficult to intubate should be screened for sleep apnea, a strong risk factor of difficult intubation in our study. However,

TABLE 4. RESULTS OF MULTIVARIATE LOGISTIC REGRESSION FOR FINAL DIFFICULT INTUBATION PREDICTION MODEL FROM ORIGINAL COHORT $(\mathrm{N}=694)$

\begin{tabular}{|c|c|c|c|}
\hline Variable & $\beta$ Parameter & $\begin{array}{c}\text { Odds Ratio } \\
\text { (95\% Confidence } \\
\text { Interval) }\end{array}$ & $\begin{array}{c}P \\
\text { Value }\end{array}$ \\
\hline Intercept & -2.83 & & \\
\hline Mallampati score III or IV & 2.87 & $17.67(9.28-33.60)$ & $<0.0001$ \\
\hline Obstructive apnea syndrome & 1.79 & $5.97(2.68-13.23)$ & $<0.0001$ \\
\hline Reduced mobility of cervical spline & 1.35 & $3.87(1.58-9.52)$ & 0.003 \\
\hline Limited mouth opening & 1.17 & $3.21(1.34-7.70)$ & 0.009 \\
\hline Severe hypoxemia $(<80 \%)$ & 0.90 & $2.46(1.23-4.92)$ & 0.01 \\
\hline Coma & 0.81 & $2.26(1.16-4.39)$ & 0.02 \\
\hline Nonanesthesiologist & 0.71 & $2.03(1.07-3.85)$ & 0.03 \\
\hline Age & -0.02 & $0.98(0.96-1.00)$ & 0.02 \\
\hline
\end{tabular}

The model has an area under the curve of 0.90 
TABLE 5. MACOCHA SCORE CALCULATION WORKSHEET

\begin{tabular}{lr}
\hline Factors & Points \\
\hline Factors related to patient & \\
$\quad$ Mallampati score III or IV & 5 \\
Obstructive sleep apnea syndrome & 2 \\
Reduced mobility of cervical spine & 1 \\
Limited mouth opening $<3 \mathrm{~cm}$ & 1 \\
Factors related to pathology & 1 \\
Coma & 1 \\
Severe hypoxemia (<80\%) & \\
Factor related to operator & 1 \\
$\quad$ Nonanesthesiologist & 12 \\
Total &
\end{tabular}

Definition of abbreviation: MACOCHA = Mallampati score III or IV, Apnea syndrome (obstructive), Cervical spine limitation, Opening mouth $<3 \mathrm{~cm}$, Coma, Hypoxia, Anesthesiologist nontrained.

Coded from 0 to 12 : $0=$ easy; $12=$ very difficult.

Mallampati score alone was less effective than MACOCHA score to predict difficult intubation. Two factors specific to ICU patients were recognized in this study and are included in the score: severe hypoxemia before intubation and coma (Glasgow score $<8$ as a reason for intubation). Severe hypoxemia as a risk factor can be explained by a shortness of time to be adequately prepared for the intubation and perhaps by increased stress for physicians performing the procedure. Likewise, patients intubated for coma often present increased oropharyngeal secretions, limiting view of the glottis.

Moreover, the simplified score contains a factor related to the operator: a formal anesthetic training of at least 24 months. Considering the link between anesthesiology formation and difficult intubation (1), previous studies were not powered enough to show this association. A recent study (13) performed in Scotland, where almost all operators had a formal anesthetic training greater than 24 months, revealed a very low rate of difficult intubation and complications, in accordance with our study. In previous studies, the presence of two operators to perform the intubation was found as a protective factor for complications related to intubation $(1,27)$. In our opinion, the standard of care changed in France more than 8 years after these studies: the increased number of operators when difficult intubation occurred in the current study was more a consequence of difficult intubation. It is noteworthy that BMI was assessed as a risk factor for difficult intubation in univariate analysis but not in multivariate analysis. This might be explained by the important clinical overlap of BMI with other risk factors more associated with difficult intubation in the final model, such as Mallampati score, mouth opening, OSAS, or severe hypoxemia before intubation. For example, in the study by Holmberg and coworkers (28), BMI greater than $40 \mathrm{~kg} / \mathrm{m}^{2}$ in prehospital tracheal intubation was associated with difficult intubation, but other risk factors for difficult intubation were not assessed. In fact, this might mean that the risk factors associated with obesity, rather than obesity itself, are probably associated with difficult intubation in this study, as Lundstrøm and coworkers (23) revealed in the anesthesiology area, where high BMI was a weak predictor for difficult and failed tracheal intubation.

NIV failure was associated with a lower risk of difficult intubation in univariate analysis, but not in multivariate analysis. NIV before intubation has been demonstrated to prevent hypoxemia and was associated with less airway complications of intubation $(2,3)$. It is the first study to show that NIV is associated with a lower rate of difficult intubation, perhaps related to the greater duration before hypoxemia occurrence compared with other patients (3).
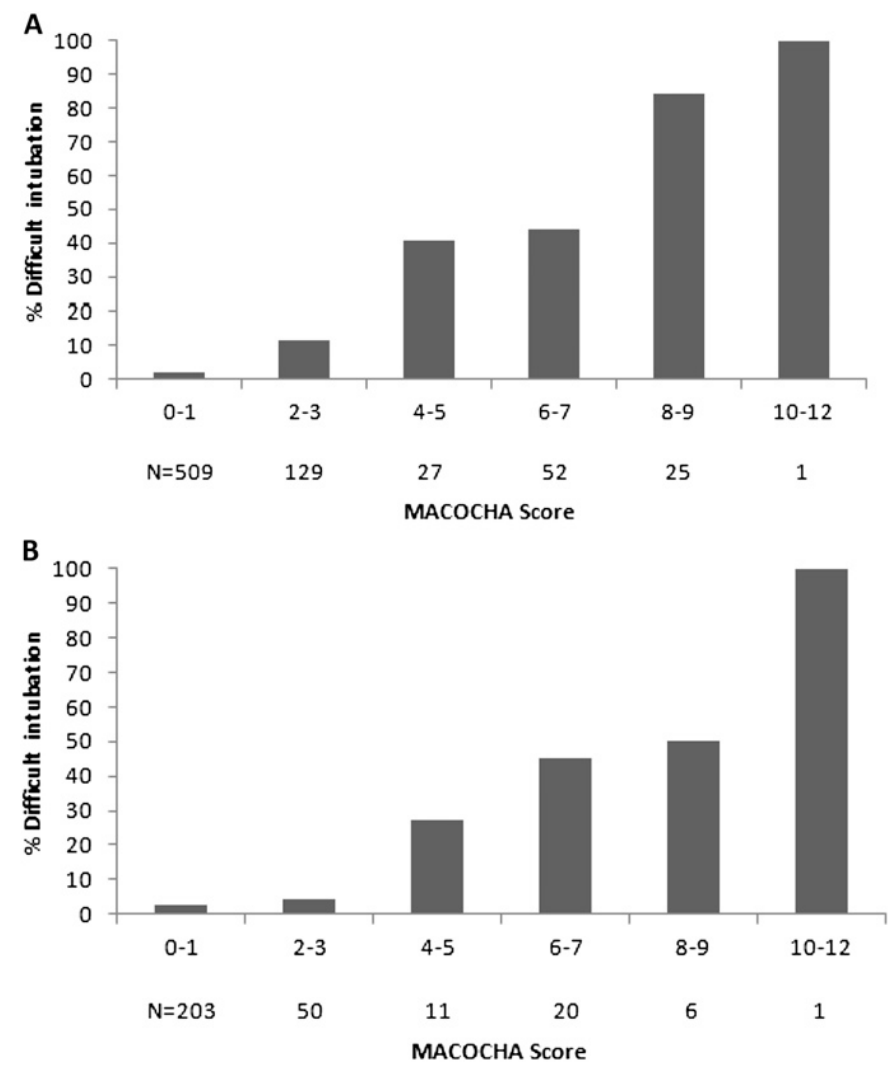

Figure 2. (A) Frequency of difficult intubation in original cohort according to the MACOCHA score. Frequency of difficult intubation with different MACOCHA score values. $\mathrm{N}=$ number of patients in the study who had particular MACOCHA score values. (B) Frequency of difficult intubation in validation cohort according to the MACOCHA score. Frequency of difficult intubation with different MACOCHA score values. $\mathrm{N}=$ number of patients in the study who had particular MACOCHA score values.

As expected, the patients with difficult intubation had a significantly higher IDS score (6 [4-8] vs. 1 [0-2]; $P<0.0001)$. It should be noted that IDS score is a surrogate of the difficulty of intubation a posteriori and not a predictive score, as the MACOCHA score validated in this study.

Capnography was used only in $46 \%$ of intubations, whereas it is recommended (8) to be always used after intubation to assess the endotracheal position of the tracheal tube. Recent studies also found a similar result, reporting capnography use between $25 \%$ (29) and 54\% (13). Systematic use of capnography could reduce the rate of complications related to intubation (2).

The study has some limitations. First, because data collection and intubation were sometimes performed by the same person, the degree of difficulty of intubation could have been overestimated or underestimated. Second, the Mallampati score was only available in $77 \%$ of the original cohort. The reasons for this might be an ignorance of the score by some operators. Moreover, Mallampati score is sometimes difficult to assess in an emergency context (30). This could be explained by the risk factors of nonassessment of Mallampati score determined in this study by multivariate logistic regression. Indeed, the need to replace the endotracheal tube is often done in emergency conditions, leaving no time to assess Mallampati score. More often, limited mouth opening, head and neck disease, or coma do not allow Mallampati score assessment. Accordingly, the modest bias induced by the lack of Mallampati score data does not influence the main results of the study. The main message remains that 
A
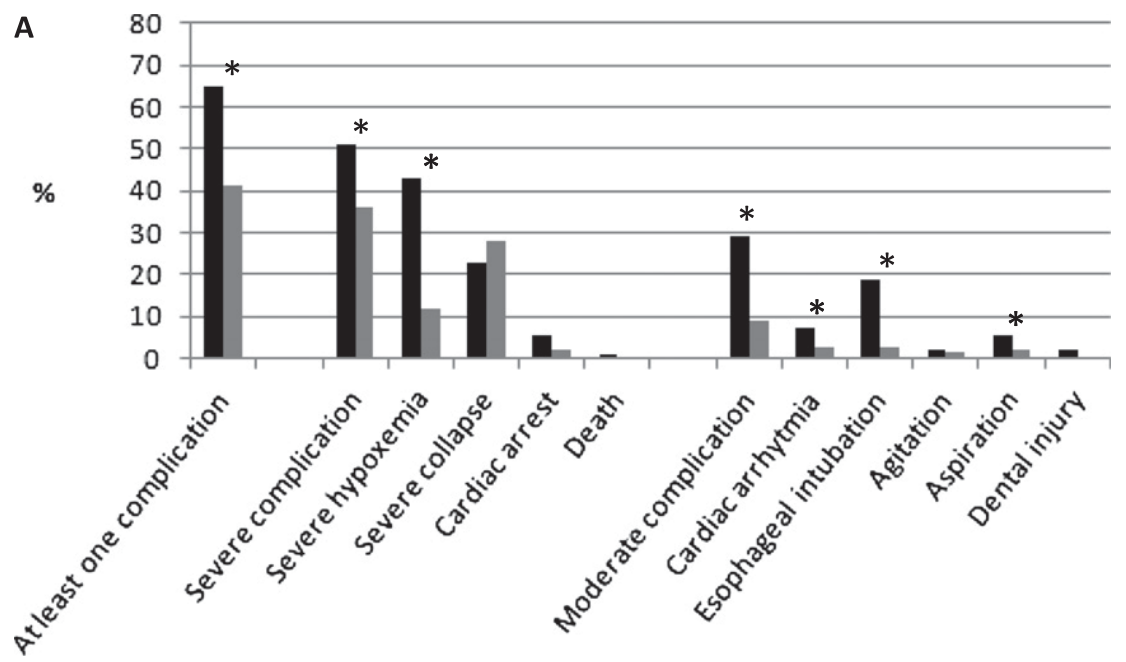

B

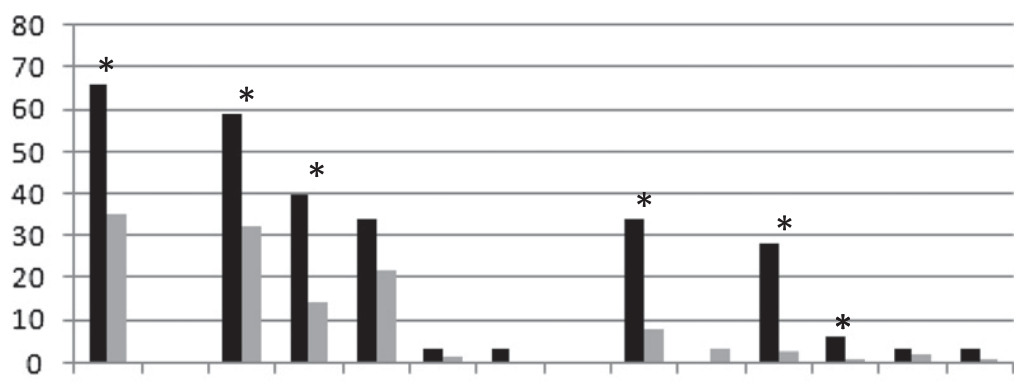

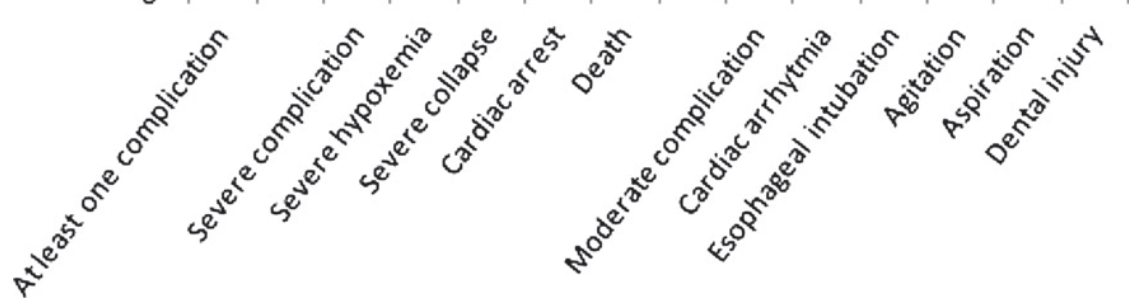

Figure 3. (A) Percentage of complications according to difficult intubation in original cohort. Black $=$ difficult intubation; gray $=$ no difficult intubation. ${ }^{*} P<0.05$. (B) Percentage of complications according to difficult intubation in validation cohort. Black = difficult intubation; gray $=$ no difficult intubation. ${ }^{*} P<0.05$.
Mallampati scores should be evaluated as often as possible. In our study, Mallampati score was assessed in recumbent patients. Performance of Mallampati score with a recumbent patient is at least as good as in a sitting position, according to previous studies (31-34). The only situation where such an assessment is not possible is when the patient presents a much altered consciousness, which is also a risk factor for difficult intubation according to the current study. Besides, other missing data were very low. Third, it is a multicenter study, which is a strength because the result can be better extrapolated to the general population, and a limit because of unequal distribution intubation numbers among centers. However, the center effect was assessed and not retained. Fourth, the external validation was performed in French ICUs and not in other countries, which could limit the extrapolation of the results. Fifth, a statistical model for repeated data was not used despite several intubation procedures for a same patient included in the analysis. Yet, the number of patients who have been intubated at least twice was low in both cohorts $(<1 \%)$. As a consequence, the bias is very limited. Sixth, neck circumference was estimated rather than measured. This parameter has to be considered with caution. Finally, intubation is a procedure that depends greatly on the intrinsic quality of the operator, which is hardly assessable in clinical studies.

To conclude, this is the first study to develop and validate a score predicting the difficulty of intubation procedure in the ICU with a high discriminative ability. The MACOCHA score is very easy to perform and to memorize. However, if the score does not predict a difficult intubation, one should remain vigilant because there is still a small possibility that it will be difficult. Mallampati score is the highest predictor of difficult intubation and should be evaluated as often as possible before intubation in the ICU. Complications of intubation are strongly associated with difficult intubation. Further studies are needed to appreciate if applying the MACOCHA score in daily practice helps to anticipate and further reduce complications of intubation.

Acknowledgment: The authors thank Valérie Macioce (Statistic Department of Montpellier Hospital) for the English editing; and Ericka Nogue and Audrey Jaussent for their methodologic advice (Statistic Department of Montpellier Hospital).

Members of the Frida-Réa Study Group: Dr. Ammenouche, Amiens; Pr. Dupont, Amiens; Dr. Crombes, CH Arles; Dr. Courant, Avignon; Dr. Pradel, Avignon; Dr. Closon, Bourg en Bresse; Dr. Desmeulles, Caen; Dr. Terzi, Caen; Dr. Doise, Chalon; Dr. Constantin-Cayot, Clermont-Ferrand; Pr. Constantin, Clermont-Ferrand; Dr. Mehdaoui, Fort de France; Dr. Potton, Grenoble; Pr. Timsit, Grenoble; Dr. Durand, Grenoble; Pr. Payen, Grenoble; Dr. Winer, La Réunion; Dr. Roussiaux, La Réunion; Dr. Claud, Le Puy en Velay; Pr. Guérin, Lyon; Pr. Allaouchiche, Lyon; Dr. Wallet, Lyon; Dr. Mokart, Marseille; Dr. Hraiech, Marseille; Pr. Papazian, Marseille; Dr. Hammad, Marseille; Pr. Leone, Marseille; Pr. Michelet, Marseille; Pr. Gainnier, Marseille; Dr. Jung, Montpellier; Dr. Chanques, Montpellier; Dr. De Jong, Montpellier; Pr. Jaber, Montpellier; Dr. Corne, Montpellier; Pr. Capdevila, Montpellier; Dr. Lakhal, Montpellier; Dr. Perrigault, Montpellier; Dr. Trine, Montpellier; Pr. Mertes, Nancy; Pr. Asehnoune, Nantes; Dr. Guitton, Nantes; Dr. Larcher, Narbonne; Pr. Ichai, Nice; Pr. Lefrant, Nîmes; Dr. Muller, Nîmes; Dr. Bengler, Nimes; Dr. Bonnieux Papeete; Pr. Paugam, Paris; Dr. Bronchard, Paris; Pr. Vigue, Paris; Dr. Raux, Paris; Pr. Langeron, Paris; Dr. Mongardon, Paris; Pr. Demoule, Paris; Dr. Garrouste, Paris; Dr. Maziers, Paris; Pr. Azoulay, Paris; Dr. Marret, Paris; Dr. Fartoukh, Paris; Dr. Blot, Paris; Dr. Quintard, Perpignan; Pr. Mimoz, Poitiers; Dr. Frat, Poitiers; Pr. Seguin, Rennes; Dr. Beurret, Roanne; Dr. Mofredj, Salon-de-Provence; Dr. Mahul, Saint-Etienne; Dr. Ramakers, Saint-Lo; Dr. Pottecher, Strasbourg; Dr. Arnal, Toulon; Dr. Goutorbe, Toulon; and Dr. Riu, Toulouse. 


\section{References}

1. Jaber S, Amraoui J, Lefrant J-Y, Arich C, Cohendy R, Landreau L, Calvet Y, Capdevila X, Mahamat A, Eledjam J-J. Clinical practice and risk factors for immediate complications of endotracheal intubation in the intensive care unit: a prospective, multiple-center study. Crit Care Med 2006;34:2355-2361.

2. Jaber S, Jung B, Corne P, Sebbane M, Muller L, Chanques G, Verzilli D, Jonquet O, Eledjam J-J, Lefrant J-Y. An intervention to decrease complications related to endotracheal intubation in the intensive care unit: a prospective, multiple-center study. Intensive Care Med 2010;36:248-255.

3. Baillard C, Fosse J-P, Sebbane M, Chanques G, Vincent F, Courouble P, Cohen Y, Eledjam J-J, Adnet F, Jaber S. Noninvasive ventilation improves preoxygenation before intubation of hypoxic patients. Am J Respir Crit Care Med 2006;174:171-177.

4. Peterson GN, Domino KB, Caplan RA, Posner KL, Lee LA, Cheney FW. Management of the difficult airway: a closed claims analysis. Anesthesiology 2005;103:33-39.

5. Cook TM, Woodall N, Harper J, Benger J. Major complications of airway management in the UK: results of the Fourth National Audit Project of the Royal College of Anaesthetists and the Difficult Airway Society. Part 2: intensive care and emergency departments. $\mathrm{Br}$ J Anaesth 2011;106:632-642.

6. Jabre P, Avenel A, Combes X, Kulstad E, Mazariegos I, Bertrand L, Lapostolle F, Adnet F. Morbidity related to emergency endotracheal intubation: a substudy of the KETAmine SEDation trial. Resuscitation 2011;82:517-522.

7. Robbertze R, Posner KL, Domino KB. Closed claims review of anesthesia for procedures outside the operating room. Curr Opin Anaesthesiol 2006;19:436-442.

8. Practice guidelines for management of the difficult airway: an updated report by the American Society of Anesthesiologists Task Force on Management of the Difficult Airway. Anesthesiology 2003;98:1269-1277.

9. Mort TC. Emergency tracheal intubation: complications associated with repeated laryngoscopic attempts. Anesth Analg 2004;99:607-613.

10. Martin LD, Mhyre JM, Shanks AM, Tremper KK, Kheterpal S. 3,423 emergency tracheal intubations at a university hospital: airway outcomes and complications. Anesthesiology 2011;114:42-48.

11. Heuer JF, Barwing TA, Barwing J, Russo SG, Bleckmann E, Quintel M, Moerer O, Mörer O. Incidence of difficult intubation in intensive care patients: analysis of contributing factors. Anaesth Intensive Care 2012; 40:120-127.

12. Le Tacon S, Wolter P, Rusterholtz T, Harlay M, Gayol S, Sauder P, Jaeger A. Complications of difficult tracheal intubations in a critical care unit. Ann Fr Anesth Reanim 2000;19:719-724.

13. Simpson GD, Ross MJ, McKeown DW, Ray DC. Tracheal intubation in the critically ill: a multi-centre national study of practice and complications. Br J Anaesth 2012;108:792-799.

14. Practice guidelines for management of the difficult airway. A report by the American Society of Anesthesiologists Task Force on Management of the Difficult Airway. Anesthesiology 1993;78:597-602.

15. España PP, Capelastegui A, Gorordo I, Esteban C, Oribe M, Ortega M, Bilbao A, Quintana JM. Development and validation of a clinical prediction rule for severe community-acquired pneumonia. Am J Respir Crit Care Med 2006;174:1249-1256.

16. Diepgen TL, Sauerbrei W, Fartasch M. Development and validation of diagnostic scores for atopic dermatitis incorporating criteria of data quality and practical usefulness. J Clin Epidemiol 1996;49:1031-1038.

17. Steyerberg EW, Harrell FE Jr, Borsboom GJ, Eijkemans MJ, Vergouwe Y, Habbema JD. Internal validation of predictive models: efficiency of some procedures for logistic regression analysis. J Clin Epidemiol 2001;54:774-781.

18. Shiga T, Wajima Z, Inoue T, Sakamoto A. Predicting difficult intubation in apparently normal patients: a meta-analysis of bedside screening test performance. Anesthesiology 2005;103:429-437.

19. Hirsch-Allen AJ, Ayas N, Mountain S, Dodek P, Peets A, Griesdale DEG. Influence of residency training on multiple attempts at endotracheal intubation. Can J Anaesth 2010;57:823-829.

20. Ray P, Le Manach Y, Riou B, Houle TT. Statistical evaluation of a biomarker. Anesthesiology 2010;112:1023-1040.

21. Bleeker SE, Moll HA, Steyerberg EW, Donders ART, Derksen-Lubsen G, Grobbee DE, Moons KGM. External validation is necessary in prediction research: a clinical example. J Clin Epidemiol 2003;56: 826-832.

22. Naguib M, Scamman FL, O'Sullivan C, Aker J, Ross AF, Kosmach S, Ensor JE. Predictive performance of three multivariate difficult tracheal intubation models: a double-blind, case-controlled study. Anesth Analg 2006;102:818-824.

23. Lundstrøm LH, Møller AM, Rosenstock C, Astrup G, Wetterslev J. High body mass index is a weak predictor for difficult and failed tracheal intubation: a cohort study of 91,332 consecutive patients scheduled for direct laryngoscopy registered in the Danish Anesthesia Database. Anesthesiology 2009;110:266-274.

24. L'Hermite J, Nouvellon E, Cuvillon P, Fabbro-Peray P, Langeron O, Ripart J. The Simplified Predictive Intubation Difficulty Score: a new weighted score for difficult airway assessment. Eur J Anaesthesiol 2009;26:1003-1009.

25. Yildiz TS, Korkmaz F, Solak M, Toker K, Erciyes N, Bayrak F, Ganidagli S, Tekin M, Kizilkaya M, Karsli B, et al. Prediction of difficult tracheal intubation in Turkish patients: a multi-center methodological study. Eur J Anaesthesiol 2007;24:1034-1040.

26. Hiremath AS, Hillman DR, James AL, Noffsinger WJ, Platt PR, Singer SL. Relationship between difficult tracheal intubation and obstructive sleep apnoea. Br J Anaesth 1998;80:606-611.

27. Boylan JF, Kavanagh BP. Emergency airway management: competence versus expertise? Anesthesiology 2008;109:945-947.

28. Holmberg TJ, Bowman SM, Warner KJ, Vavilala MS, Bulger EM, Copass MK, Sharar SR. The association between obesity and difficult prehospital tracheal intubation. Anesth Analg 2011;112:11321138 .

29. Georgiou AP, Gouldson S, Amphlett AM. The use of capnography and the availability of airway equipment on Intensive Care Units in the UK and the Republic of Ireland. Anaesthesia 2010;65:462467.

30. Levitan RM, Everett WW, Ochroch EA. Limitations of difficult airway prediction in patients intubated in the emergency department. Ann Emerg Med 2004;44:307-313.

31. Tham EJ, Gildersleve CD, Sanders LD, Mapleson WW, Vaughan RS Effects of posture, phonation and observer on Mallampati classification. Br J Anaesth 1992;68:32-38.

32. Bindra A, Prabhakar H, Singh GP, Ali Z, Singhal V. Is the modified Mallampati test performed in supine position a reliable predictor of difficult tracheal intubation? J Anesth 2010;24:482-485.

33. Singhal V, Sharma M, Prabhakar H, Ali Z, Singh GP. Effect of posture on mouth opening and modified Mallampati classification for airway assessment. J Anesth 2009;23:463-465.

34. Lewis M, Keramati S, Benumof JL, Berry CC. What is the best way to determine oropharyngeal classification and mandibular space length to predict difficult laryngoscopy? Anesthesiology 1994;81:69-75. 